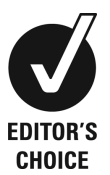

CHOICE

\title{
Renal cell carcinoma with proliferative lupus nephritis
}

\author{
Koh-Wei Wong
}

Department of Medicine, Hospital Queen Elizabeth, Kota Kinabalu, Sabah, Malaysia

\section{Correspondence to Dr K-W Wong, drwongkohwei@gmail.com}

Accepted 26 December 2014

\section{SUMMARY}

We report a case of renal cell carcinoma diagnosed after a patient was treated successfully with intravenous cyclophosphamide for her active proliferative lupus nephritis (classes III and V). After the intravenous cyclophosphamide regimen, the patient was asymptomatic with persistent microscopic haematuria, and no proteinuria. The renal cell carcinoma was located on the left kidney; incidentally, this was where the initial renal biopsy was done to diagnose lupus nephritis.

\section{BACKGROUND}

The kidney is one of the common organs affected by systemic lupus erythematosus (SLE), and involvement of the kidneys (lupus nephritis) may warrant aggressive treatment involving immuosuppressives to induce remission. Intravenous cyclophosphamide has been the mainstay of treatment of active lupus nephritis, especially for class III or IV.

We described a case of active lupus nephritis, with persistent microscopic haematuria after the patient was in remission following an induction regimen using intravenous cyclophosphamide, and a diagnosis of renal cell carcinoma of the left kidney.

\section{CASE PRESENTATION}

A 52-year-old woman was admitted in March 2012 for seizures. She was subsequently diagnosed as having SLE. Investigations revealed a serum albumin of $31 \mathrm{~g} / \mathrm{L}$, serum creatinine of $89 \mu \mathrm{mol} / \mathrm{L}$, proteinuria of $2.23 \mathrm{~g} / \mathrm{day}$, and positive antinuclear antibodies and anti-double stranded antibodies as well as hypocomplementaemia. She was admitted again in April 2012 with a basal ganglia infarct. Renal biopsy from the lower pole of the left kidney was performed in May 2012. The renal biopsy was reported as focal proliferative and sclerosing with an early membranous pattern, a full house pattern on immunofluorescense study, International Society of Nephrology/Renal Pathology Society classes III $(\mathrm{A} / \mathrm{C})$ and $\mathrm{V}$, with no significant chronic tubulointerstitial damage. The Activity Index was $8 / 24$ and the Chronicity Index was $0 / 12$.

She was given an induction regimen of intravenous cyclophosphamide, $1 \mathrm{~g} /$ dose/month for six doses. She received a cumulative dose of $6 \mathrm{~g}$ and achieved remission (serum creatinine $99 \mu \mathrm{mol} / \mathrm{L}$, serum albumin $45 \mathrm{~g} / \mathrm{L}$, proteinuria $0.21 \mathrm{~g} /$ day). She was then started on oral mycophenolate mofetil (MMF) as her maintenance therapy $(750 \mathrm{mg}$ twice daily). Her other medications were low dose prednisolone (5 $\mathrm{mg}$ once daily), hydroxychloroquine
$200 \mathrm{mg}$ once daily, perindopril $8 \mathrm{mg}$ once daily, felodipine $10 \mathrm{mg}$ once daily, aspirin $75 \mathrm{mg}$ once daily, ranitidine $150 \mathrm{mg}$ once daily, potassium chloride tablet $600 \mathrm{mg}$ once daily and calcium carbonate $500 \mathrm{mg}$ twice daily. She remained well during her regular follow-up, with a normal erythrocyte sedimentation rate (ESR), and normal renal function and serum albumin.

However, it was noted that despite the fact that her proteinuria had disappeared, she had persistent microscopic haematuria. An ultrasound was performed in October 2013 which showed an exophytic mass at the left kidney. This was followed by CT (four phases) in November 2013, which showed a left renal mass measuring $5.6 \mathrm{~cm} \times 5.0 \mathrm{~cm} \times 6.4 \mathrm{~cm}$, situated at the upper and mid-pole splaying the renal calyx, homogenous with a central hypodense region on plain phase, with significant peripheral enhancement on the nephrographic, corticomedullary and excretory phases. The impression was left renal cell carcinoma with subcentimetre para-aortic node metastasis.

Mycophenolate was stopped and a urology referral was made. Laparoscopic nephrectomy was performed in December 2013. Histopathological examination of the left kidney revealed renal cell carcinoma, chromophobe type Fuhman grade II, PT1 Nx Mx; there was no lymphovascular invasion, and the ureteric margin, renal vessels and Gerrotas fascial margins were free of tumour.

\section{OUTCOME AND FOLLOW-UP}

Six months after nephrectomy she remained stable, with no signs of lupus activity (proteinuria negative, normal ESR). The original renal biopsy was revised again, and there was no evidence of renal cell carcinoma.

\section{DISCUSSION}

Prior to renal biopsy, ultrasound examination did not reveal any renal mass. Due to the persistent microscopic haematuria, she was referred to the surgical clinic for a urological assessment, and ultrasound revealed the renal mass. She was completely asymptomatic for SLE and renal cell carcinoma during this period.

\section{Persistent microscopic haematuria}

Proteinuria and microscopic haematuria are common findings in patients with lupus nephritis. In patients who achieve remission after induction treatment for class III and class IV lupus nephritis, most will have little proteinuria during the remission period. However, persistent microscopic haematuria with no or minimal proteinuria is common in patients with 
lupus nephritis, even after they have achieved full clinical remission (little or no proteinuria, normal renal function, and normal ESR and complement levels). Low level activity of lupus nephritis after the induction therapy may be a reasonable explanation for the persistent microscopic haematuria. ${ }^{1}$ There are other possible causes. Mittal et al ${ }^{1}$ reported a concomitant presence of thin basement membrane disease with lupus nephritis class IV, a case which was also treated with intravenous cyclophosphamide to induce remission, but the patient had persistent microscopic haematuria despite the fact that clinically, disease activity appeared to be low. As in our case, it is important not to assume that persistent microscopic haematuria is solely due to lupus nephritis or chronic damage from lupus nephritis.

\section{Cyclophosphamide and cancer}

Cyclophosphamide has been known to be associated with the development of malignancy, especially bladder cancer. ${ }^{2}{ }^{3}$ It is also reported to be associated with haematological malignancies. ${ }^{2-8}$ It appears to be dose related, as reported by Travis et $a l^{3}$ and Radis et al; ${ }^{4}$ the higher the cumulative dose, the higher the risk of bladder cancer. Many of the bladder cancers developed years after discontinuation of cyclophosphamide. ${ }^{2-4}$

Most renal cell carcinomas associated with cyclophosphamide are reported in transplant recipients. In 1996, Odeh ${ }^{5}$ reported the first case of renal cell carcinoma after treatment with cyclophosphamide in a patient with Wegener's granulomatosis. Most authors reported simultaneous diseases of Wegener's granulomatosis and renal cell carcinoma, suggesting common pathogenetic pathways, and others have reported the development of renal cell carcinoma many years after discontinuation of cyclophosphamide. ${ }^{8}$

In our case, development of renal cell carcinoma was within 12 months after discontinuation of cyclophosphamide. There is a possibility that renal cell carcinoma was present during the diagnosis of active lupus nephritis, and that it could have been missed at the initial ultrasound. Subsequent cyclophosphamide treatment could have accelerated the growth of the cancer.

To date, there has been no reported case of any simultaneous occurrence of lupus nephritis and renal cell carcinoma. There is also no known association between the two diseases.

\section{MMF and cancer}

MMF has been used extensively in transplantation. ${ }^{9-11}$ A prospective cohort observational study ${ }^{10}$ did not find any association between MMF and an increased risk of lymphoma or other malignancies post-renal transplantation. In fact, use of MMF was reported to be associated with a lower risk of developing malignancy, both in the study by Robson et al and in a group of post-heart transplant patients. ${ }^{11}$

Apart from transplantation, MMF is also widely used in patients with SLE and other autoimmune diseases. Vernino et $a l^{9}$ reported a case of primary CNS tumour in a patient with myasthenia gravis after 3 years of treatment with MMF. To date there has been no other reported association between MMF and the development of malignancy.

\section{Lupus and malignancy}

There may be a slightly increased risk of cancer in SLE patients compared with the general population, but that seems to be mainly due to the increased incidence of haematological malignancies, especially non-Hodgkin's lymphoma. ${ }^{12} 13$ The underlying mechanism of the association between lupus and malignancy is still uncertain, and medication exposure seems to be the main culprit. To date, there has been no reported association between lupus nephritis and renal cell carcinoma.

\section{CONCLUSION}

Development of malignancy usually occurs in patients many years after cyclophosphamide exposure. Cyclophosphamide has been widely used in treating active lupus nephritis, especially class III or IV. The cyclophosphamide dose used to treat lupus nephritis is much less compared with the regimen used for treating other cancers. In our patient, the cumulative dosage was $6 \mathrm{~g}$. The temporal relationship of the diagnosis of lupus nephritis, treatment with cyclophosphamide, dosage used and diagnosis of renal cell carcinoma in our patient may suggest that renal cell carcinoma was present before or during the diagnosis of active lupus nephritis. It is important not to assume that the presence of persistent microscopic haematuria in a lupus patient clinically in remission is benign.

\section{Learning points}

- Some patients may have persistent microscopic haematuria after the induction regimen for lupus nephritis.

- It is important not to assume that the presence of persistent microscopic haematuria in a lupus patient clinically in remission to be benign.

- It is important to investigate and to look for potential malignancy in this group of patients.

Acknowledgements We thank the Director General, Ministry of Health, for approval to publish this article.

Competing interests None.

Patient consent Obtained.

Provenance and peer review Not commissioned; externally peer reviewed.

\section{REFERENCES}

1 Mittal BV, Pendse S, Rennke HG, et al. Hematuria in a patient with class IV lupus nephritis. Kidney Int 2006;70:1182-6.

2 Vasquez S, Kavanaugh AF, Schneider NR, et al. Acute nonlymphocytic leukemia after treatment of systemic lupus erythematosus with immunosuppressive agents. J Rheumatol 1992;19:1625-7.

3 Travis LB, Curtis RE, Glimelius B, et al. Bladder and kidney cancer following cyclophosphamide therapy for non-Hodgkin's lymphoma. J Natl Cancer Inst 1995;87:524-30

4 Radis CD, Kahl LE, Baker GL, et al. Effects of cyclophosphamide on the development of malignancy and on long-term survival of patients with rheumatoid arthritis. A 20-year followup study. Arthritis Rheum 1995;38:1120-7.

5 Odeh M. Renal cell carcinoma associated with cyclophosphamide therapy for Wegener's granunomatosis. Scan J Rheumatol 1996;25:391-3.

6 Bernatsky S, Ramsey-Goldman R, Clarke AE. Malignancies and cyclophosphamide exposure in Wegener's granulomatosis. J Rheumatol 2008;35:11-13.

7 Bernatsky S, Clarke AE, Suissa S. Hematologic malignant neoplasms after drug exposure in rheumatoid arthritis. Arch Intern Med 2008;168:378-81.

8 Deger SM, Mutluay R, Ebinc FA, et al. Renal cell carcinoma associated immunosuppressive therapy: a case report with Wegener's granulomatosis. Rheumatol Int 2009;30:119-21.

9 Vernino S, Salomao DR, Habermann TM, et al. Primary CNS lymphoma complicating treatment of myasternia gravis with mycophenolate mofetil. Neurology 2005;65:639-41

10 Robson R, Cecka JM, Opelz G, et al. Prospective registry-based observational cohort study of the long-term risk of malignancies in renal transplant patients treated with mycophenolate mofetil. Am J Transplant 2005;5:2954-60.

11 O'Neill JO, Edwards LB, Taylor DO. Mycophenolate mofetil and risk of developing malignancy after orthotopic heart transplantation: analysis of the transplant registry of the International Society for Heart and Lung Transplantation. J Heart Lung Transplant 2006;25:1186-91.

12 Bernatsky S, Ramsey-Goldman R, Clarke AE. Malignancy in systemic lupus erythematosus: what have we learned? Best Pract Res Clin Rheumatol 2009;23:539-47.

13 Bernatsky S, Kale M, Ramsey-Goldman R, et al. Systemic lupus and malignancies. Curr Opin Rheumatol 2012;24:177-81. 
Copyright 2015 BMJ Publishing Group. All rights reserved. For permission to reuse any of this content visit http://group.bmj.com/group/rights-licensing/permissions.

BMJ Case Report Fellows may re-use this article for personal use and teaching without any further permission.

Become a Fellow of BMJ Case Reports today and you can:

- Submit as many cases as you like

- Enjoy fast sympathetic peer review and rapid publication of accepted articles

- Access all the published articles

- Re-use any of the published material for personal use and teaching without further permission

For information on Institutional Fellowships contact consortiasales@bmjgroup.com

Visit casereports.bmj.com for more articles like this and to become a Fellow 